variety.) Walker has investigated in detail, using two-dimensional Fourier syntheses, the dehydration mechanism in vermiculite, and his paper may well form the foundation for much future thought on clay-water relationships, replacing the earlier ideas of Hendricks and Jefferson ${ }^{5}$. He recognizes a twolayer stage for the interlamellar water, with octahedral co-ordination around the exchange cations; then a less hydrous stage where the cations migrate to the mineral surface, followed by a one-layer stage ; and finally, as more water is removed, the 'collapsed' form without interlamellar water occurs in interstratification with the previous stage.

Walker's paper was read during a symposium on "Clay-Water Relationships", in which H. van Olphen presented experimental evidence for the magnitude of the linking force in pure clay gels $\left(10^{-4}\right.$ dynes), and the height of the energy barrier for thixotropic gelling in $0.03 \mathrm{~N}$ sodium chloride solution $(7 k T)$. In the same session, D. T. Oakes and E. J. Burcik described a method for electro-osmotic charge determination in concentrated suspensions; W. H. Wood, W. T. Granquist and I. M. Krieger described viscosity measurements on very dilute suspensions ; W. C. Ormsby, R. M. Witucki and W. A. Weyl reported investigations on the effect of wetting agents on deformation of kaolinite suspensions; and U. Hofmann gave experimental evidence for a relation between surface charge of montmorillonite minerals (determined by chemical analysis) and swelling properties. C. W. Marshall, who was unable to be present, sent a paper on thermodynamic, quasithermodynamic and non-thermodynamic methods of investigating the electrochemistry of clays.

Another symposium was devoted to "Thermal Transformations in Clay Minerals". R. A. Rowland, E. J. Weiss and W. F. Bradley reported on the study of mono-ionic montmorillonites ( $\mathrm{Na}, \mathrm{K}, \mathrm{Li}, \mathrm{NH}_{4}, \mathrm{H}$, $\mathrm{Ca}, \mathrm{Mg}, \mathrm{Mn}$ ), using the 'oscillating-heating' method, which consists in continuously scanning a small diffraction region, while heating the sample. The resulting diagrams illustrate very prettily the onset and progress of reactions. J. L. White described work on the effects of molten salts on layer-lattice silicates, the most striking result being the removal of potassium from (silt- and clay-grade) mica by molten lithium nitrate, giving a montmorillonite-like product. Other papers were on the dehydroxylation of illite (B. W. Nelson), and comparison of natural and synthetic montmorillonites (L. B. Sand and M. S. Crowley).

Advances in the technique of identification of minerals were referred to by E. B. Kinter and S. Diamond, and I. H. Milne and C. M. Wardshaw (preparation of samples for an X-ray diffractometer); and by A. Auskern and R. W. Grimshaw (infra-red spectrography). Aspects of industrial interest included paper-coating by kaolinite (H. H. Murray and S. C. Lyons); green compression strengths of bentonites (W. F. Bradley); and colloidal properties of silica and silicones (E. A. Hauser).

There was no symposium on weathering and alteration of minerals, but several papers were concerned with related questions. In Illinois $(H$. $H$. Murray and R. K. Leininger), and in Wisconsin (L. D. Whittig and M. L. Jackson), illite and chlorite have been found to alter to montmorillonoid (montmorin), or vermiculite. B. N. Rolfe described surficial sediments from Lake Mead (Hoover Dam area). B. Osthaus has studied the acid dissolution of montmorillonite and nontronite, and is able to distinguish two first-order reactions in the removel of iron and aluminium (octahedral and tetrahedral co-ordination ?). G. T. Kerr, R. H. Zimmerman and F. H. Wells have found two stages in the degradation of acid hectorite, with the release first of magnesium, and then of silicon dioxide. Anion exchange was discussed by S. J. Buckwold.

The entire series of meetings gave an impressive picture of clay mineral researches in the United States at the present time. It is noteworthy that some fine pieces of research have been done by industrial laboratories, especially those of oil companies. Most of the foreign visitors seemed to find the programme over-full, and would have preferred more time. This conference represented, of course, a year's research in the field. As compared with the diversity of effort in Europe (two meetings a year in Great Britain, France and Sweden ; and others in Germany, Belgium, etc.) it showed the great advantages of organization on a continental scale, enabling all the workers on the subject to get together for an intensive discussion. The result was very inspiring. The complete proceedings of the conference will appear in book form, and are at present being edited by Miss Ada Swineford, of the Kansas Geological Survey. Like the second and third conferences, they will be published by the National Research Council, Washington, D.C., as will, so it is intended, the proceedings of subsequent conferences. The proceedings of the first (Bull. 169, Calif. Dept. of Mines, 1955) and second conferences have already appeared and form attractive and valuable records of progress in this field.

D. M. C. MACEwaN

${ }^{1}$ Alexander, L. T., Hendricks, S. B., and Nelson, R. A., Soil Sei., 48, 273 (1939).

2 Lippmann, F., Heidelberger Beitr. Min. Petr., 4, 130 (1954).

3 Byström, A.-M., Nature, 173, 783 (1954).

4Caillère, S., and Hénin, S., C.R. Acad. Sci., Paris, 230, 668 (1950).

s Hendricks, S. B., and Jefferson, M. E., Amer. Min., 23, 855 (1938).

\section{THE METAPHYSICS OF SCIENCE}

TN the Riddell Memorial Lectures* Prof. R. O. 1 Kapp discusses a question which is, he says, of even greater importance for science than for theology, namely, "whether non-material influences have a real existence or not" (p. 8). Kapp defends an affirmative answer to this question, a doctrine that he calls "dualism", as against the negative thesis which he describes as "monism". This nomenclature is, I think, misleading, because various theorists such as Hegel have advocated a non-material, that is, spiritual, monism. Kapp supposes not only that the two metaphysical theories of dualism and monism are answers to a genuine problem, roughly 'What are the ultimate and irreducible constituents of reality ?', but also that they are the only two possible answers to the problem. These are, of course, very large assumptions indeed, and it is regrettable that Kapp fails not only to defend them but even to state them. He gives no grounds for presenting us with what, to my mind, are equally erroneous doctrines, nor for his assumption that one must vote for one rather than the other.

Kapp regards his problem as raising an empirical issue, namely, whether or not a certain sort of entity exists. The dualism that he defends is a causal

* "Facts and Faith". By Reginald 0. Kapp. Riddell Memoria Lectures. University of Durham. Pp. 63. (Oxford University Press,
1955.) 58. 
hypothesis to account for the existence of 'order' in the universe. In this sense, which we shall see is a somewhat special one, order is explicable only if there exists a non-material cause or causes; of these we are offered a generous selection: "God, the soul, entelechy, élan vitale". The generic name given to these is "diathetes". At various places they are described as "things" (p. 13), "active realities" (p. 12) and "influences" (p. 8), but it seems clear that Kapp thinks of them as entities of a kind, as he is perplexed by the problem "That diathetes, be they called God, life, mind or the soul can be nowhere and yet do things is a most puzzling concept" (p. 53). We are not told whether these "diathetes" are fundamentally one, or whether they are separate; if the latter, then criteria should be given which would enable us to decide how many diathetes there are.

The argument that is advanced for the existence of diathetes is of the form of a causal hypothesis; they are said to be necessary to account for the existence of 'order' in the physical world. (It is not clear whether Kapp would regard as admissible any more direct attempt to establish their existence.) Only a certain class of physical events is the result of the causal activity of diathetes, those which occur in "living substance" ; this notion is contrasted with that of the "rough untouched world of lifeless things", a phrase which recurs with hypnotic regularity. "A diathete can exercise direct control over any living substance and either only indirect control or none over all lifeless substance" (p. 17). A diathete is thus very like the driver of a motor-car-indeed this simile is explicitly used on p. 21. The crux of Kapp's argument is therefore the distinction between random and ordered events; only in living substance, he maintains, is order to be found, which is the result of 'diathetic' activity, while no such hypothesis is necessary in order to understand the processes of inanimate Nature, for these are all random.

What exactly is to be understood by the phrase 'the natural order' is, of course, a problem of the greatest importance for both philosophy and the natural sciencos. Kapp recognizes the profundity of this somewhat neglected question; but his own treatment of it, so far as I can understand, is vitiated by a serious confusion. Kapp uses the words "order" and "random" as antitheses, but not always to point the same contrast. Sometimes "random" is used to mean simply "contingent" ; for example, he describes the world studied by physics as "one in which anything may happen that is logically possible" (p. 36). From this quite true observation Kapp concludes in most misleading language that such a world is a 'random' one. The bounds of logical possibility are very wide, and include many concepts that are empirically impossible; as Russell has pointed out, there is no logical absurdity in the idea that the universe was created five minutes ago, complete with memories. Thus from the contingency of all factual propositions it is incorrect to conclude that there are no objective physical laws; logical and empirical necessity are concepts of quite different orders.

In denying that there is any objective order in physical nature, Kapp finds himself faced with the problem of explaining what the physical sciences are all about ; if there are no laws in inanimate Nature, what are these sciences investigating? The discussion of this question is carried out with reference to Ohm's Law. Kapp argues, with some persuasiveness, that this principle should be regarded as a tautology, that is, as true by the definition of a resistance. With less plausibility this is alleged to hold true of all the laws of the natural sciences. In proposing a return to the conventionalism advocated by Poincaré some years ago, Kapp does not seem sufficiently aware of the objections that can be made against this view. Some of these are, briefly : (1) the fact that scientific laws can be represented as tautologies that are true by definition does not place them in any special category, for any proposition can be expressed as a tautology if sufficient latitude is allowed to our definitions; (2) if the principles of science are mere definitions, then it is not easy to understand how it is that scientific knowledge enables us to predict and control natural phenomena; (3) how, on such a theory, are we to explain, or even describe, the progress of the sciences? I do not deny that many, and perhaps all, scientific advances involve the re-definition of terms, but it by no means follows from this that the practice of science is to be understood as the invention of definitions.

A different use of the word 'random' can be found in those passages where Kapp contrasts it with the concept of 'ordered' as meaning the result of plan. ning. $\mathrm{He}$ is much concerned to omit notions like those of 'consciousness' and 'purpose' because he believes that it is a fallacy to suppose that a diathete can operate only at a conscious level. Nevertheless, he talks as if he wishes to preserve the concept of teleology without having to face the difficulties raised by the idea of 'purpose'. Thus he compares "the extremely precise predictions that can be made in the biological sciences" (a rather paradoxical remark), with the 'predictions' about the product of the assembly line that an engineer can make from blueprints (p. 49). This somewhat special use of the word 'random' is again illustrated by Kapp's remarks about the stimuli that reach the brain. Of these he says: "They are not co-ordinated. They may arrive from anywhere. [I do not know what this means.] They are random events, unselected, most of them the result of pure chance. And yet the response of the brain to these stimuli is not random. Selection, discrimination, guidance, control do occur. Where, when, how ?" (p. 20). Here 'random' clearly means 'not subject to guidance, control or selection' ; and, of course, there is a perfectly good sense of the word 'chance' which means precisely this. A boy who breaks a window 'by chance' has not broken it intentionally; but this goes no way towards showing that the event in question was a chance or random event in the scientific sense, that is, inexplicable by the known laws of mechanics or psychology. The implicit teleology of Kapp's position may also be seen from the fact that he finds no incongruity in lumping together "houses, machines and living substance" (p. 36).

The concept of 'order', which is not only of great intrinsic importance but also vital to this particular argument, is unfortunately left as obscure as its antithesis 'random'. Kapp rightly believes that the notions of 'law' and 'order' are very closely connected, but he does not notice that there is here a profound ambiguity. The discussion of the conditions of order begins with a reference to human affairs. It is argued, quite correctly, that a necessary condition of order in this sphere is law "of the statute book kind". Certainly, laws of this character, such as those governing the behaviour of traffic, introduce order, in one sense of the word, into human activity. These laws "make for order", to use a phrase which often occurs in these lectures. Kapp now passes to the 
question whether "the laws of physics are, like those in the statute books, of the kind that make for order" (p. 23). To this question, which I shall try to show is unintelligible, Kapp returns a negative answer, on the ground that, strictly speaking, there are no laws in Nature but only the definitions and conventions established by scientists. "The precision with which experiments are repeatable does not prove that it is in the nature of matter to behave in an orderly manner but only that it is in the nature of scientists to do so" (p. 45). And again : "The place of the laws of physics, we are led to conclude, is not in the world of physical reality but in the world of scientific methodology" (p. 62, Appendix). In passing, it might be observed that from this duplication of 'worlds' one can only conclude that so far as Kapp is concerned, Carnap's "Logical Syntax of Language" and Stebbing's "Philosophy and the Physicists" have been written in vain.

The problem of whether the laws of the natural sciences 'make for order' can arise, it seems to me, only as the result of a failure to recognize the ambiguity of the phrases "law" and "law and order". The traffic laws impose orderly conduct on motorists and others, and sometimes these "statute book laws", to use Kapp's somewhat unhappy phrase, may be difficult to enforce, as in Cyprus at the present time, in which case 'the rule of law' breaks down. But this does not mean that the phenomena in question become in any way unintelligible or unpredictable from the scientific standpoint. The reason for this is that 'statute book laws' are of a fundamentally different kind from those established by the sciences. The former are prescriptive rules which coerce human beings to behave in certain ways because sanctions are attached to them. Of an essentially similar kind are social rules and conventions. The laws of science (including, pace Kapp, those of biology) are entirely unlike these, for they are descriptive of the actual behaviour of the subject-matter in question, whether it be human, animal or material. Hence the laws of science do not 'make for' or impose order, for only prescriptive laws are capable of this; rather, they merely record the orderly relations which obtain between events. It is worth pointing out, incidentally, that in this distinction between prescriptive and descriptive laws, first clarified by Schlick, one can find the solution, or rather the resolution, of the problem of the freedom of the will.

In the seventeenth and eighteenth centuries this issue was somewhat bedevilled by certain theorists who represented the descriptive laws of Nature (often spelt with capitals) as prescriptive laws imposed by God on the Creation. This leads to the idea that the particles of a gas are 'governed' by Boyle's Law in the same kind of way that we are governed by the income tax laws. All this, of course, arises only from a failure to notice the different senses in which words like 'govern' and 'obey' are used. If Kapp had considered this, he could scarcely have employed language like: "Only on the reason why a particle of matter implicitly obeys the laws of physics may there be difference of opinion between a theologian and his atheistic opponent. The theologian might say it was because matter does not possess free will and cannot therefore sin against God's moral law. The atheist might object that the laws of physics were not ordained by God but by Nature and that $a$ particle of matter obeys them implicitly because it is made in Nature's image and cannot do otherwise" (p. 28). The essential point is that the laws of Nature were not ordained by anybody, so that fortunately we do not have to speculate as to what can be meant by saying that something is 'made in Nature's image'. I conclude that Kapp is right in denying that scientific laws are prescriptive, but that his reasons for this are not convincing because he fails to see that there are perfectly good laws of another, that is, descriptive, kind. If this is admitted, then it appears that Kapp's notion of order, as it concerns the natural sciences, is misconceived, and so are his attempts to find its source in 'diathetes'.

\section{K. Grant}

\section{CENTENARY OF THE FORMER SCOTTISH METEOROLOGICAL SOCIETY}

$T$ HE year 1855 saw the foundation of the Meteorological Office and the Scottish Meteorological Society, both as a result of the international conference on the meteorology of the sea held at Brussels in 1853, and the centenary of the Society's foundation was celebrated at a meeting of the Scottish centre of the Royal Meteorological Society held in Edinburgh on October 28. The principal address was delivered by Sir Ernest Wedderburn, honorary secretary of the Scottish Meteorological Society during 1909-20 and now vice-president for Scotland of the Royal Meteorological Society, and a summary of the address has been published in the November number of Weather.

Sir Ernest began by pointing out that it was Sir Henry James, then of the Scottish Ordnance Board, who proposed the formation of the Society as the best means of making available for public use the meteorological observations held by the Northern Lights. The first Council included Thomas Stevenson, designer of the Stevenson thermometer screen, and the first secretary, Dr. Stark, organized on a standard basis the work of seventy voluntary observers in Scotland and the subsequent publication of their observations by the Registrar-General. Unfortunately their preparation for publication soon had to be given up and was performed by the Astronomer-Royal for Scotland from 1858 until 1893, when it returned to the Society. In 1860, Alexander Buchan, later famous for his world climatological atlas and his work on the climate of Edinburgh, was appointed secretary, and he soon made his influence felt by arranging in 1864 for the publication of the Society's Journal, which flourished until 1920. He represented the Society at the Leipzig conference of 1872 and, with the Director of the Meteorological Office, the British Government at the Vienna conference of 1873 which did much to draw up an international code of practice in meteorological observing.

Interest in observations at high levels began early in the Society's life, and before 1870 three stations were in operation at above a thousand feet. The most famous single work of the Society, the making of observations on the summit of Ben Nevis, was first mooted in 1877 ; the observatory on the summit was opened on November 28, 1883, and hourly observations were begun and telegraphed to the Meteorological Office in London over a line laid down the mountain. In 1883 , too, the Society set up a marine research station at Granton, at which Dr. R. H. Mill began his meteorological career. 